\title{
Technical Evaluation Report for the NDMAS AGR-5/6/7 TRISO Irradiation Monitoring System
}

Binh Pham

December 2017

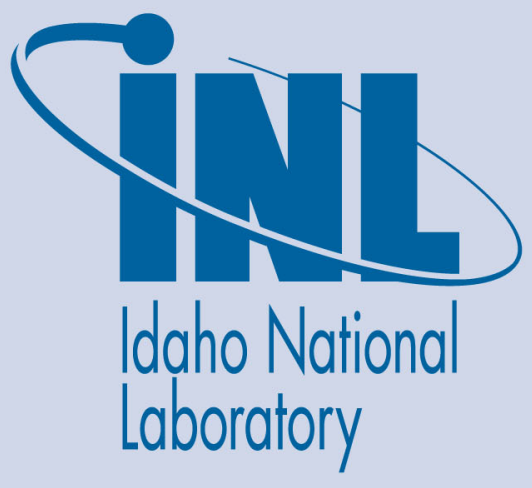

The INL is a U.S. Department of Energy National Laboratory operated by Battelle Energy Alliance 


\title{
Technical Evaluation Report for the NDMAS AGR-5/6/7 TRISO Irradiation Monitoring System
}

\author{
Binh Pham
}

December 2017

Idaho National Laboratory Idaho Falls, Idaho 83415

http://www.inl.gov

Prepared for the

U.S. Department of Energy

Under DOE Idaho Operations Office

Contract DE-AC07-05ID14517 
TEM-10300-1

$03 / 01 / 2012$

TECHNICAL EVALUATION

Page 1 of 20

Rev. 03

Title: $\quad$ NDMAS Database Reporting System for the AGR-5/6/7 Experiments

TEV No.: 3236

Rev. No.: 0

Project No.: 29412, 23841

Date: $12 / 15 / 2017$

Manual: NGNP

INL/MIS-17-44021

\section{Technical Evaluation Study}

Performer:

Binh T. Pham

C220

(Name)

(Organization)

(Signature)

(Date)

Checker ${ }^{1}$ :

Mitchell A. Plummer

(Name)

C220

(Organization)

(Signature)

(Date)

Independent Peer

Reviewer ${ }^{2}$ :

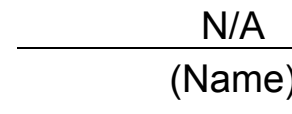

$\frac{\mathrm{N} / \mathrm{A}}{\text { (Name) }}$

$\overline{\text { (Organization) }}$

(Signature)

(Date)

CUI Reviewer:

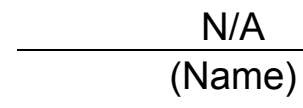

$\overline{\text { (Organization) }}$

(Signature)

(Date)

Manager ${ }^{3}$ :

Nancy J. Lybeck

(Name)

$\frac{\mathrm{C} 220}{\text { (Organization) }}$

(Signature)

(Date)

Owner":

Travis R. Mitchell

(Name)

$\frac{\text { C620 }}{\text { (Organization) }}$

(Signature)

(Date)

Nuclear Safety4:

N/A

(Name)

$\overline{\text { (Organization) }}$

(Signature)

(Date)

Quality Engineer4:

Michelle T. Sharp

H330

(Name)

(Organization)

(Signature)

(Date)

1. Confirmation of completeness, mathematical accuracy, and correctness of data and appropriateness of assumptions.

2. Concurrence of method or approach. See definition, LWP-10106.

3. Concurrence of procedure compliance. Concurrence with method/approach and conclusion.

4. Concurrence with the document's assumptions and input information. See definition of Acceptance, LWP-10300. 
TEM-10300-1

$03 / 01 / 2012$

TECHNICAL EVALUATION

Page 2 of 20

Rev. 03

Title: $\quad$ NDMAS Database Reporting System for the AGR-5/6/7 Experiments

$\begin{array}{lllll}\text { TEV No.: } 3236 & \text { Rev. No.: } 0 & \text { Project No.: } 29412,23841 & \text { Date: } 12 / 15 / 2017\end{array}$

\begin{tabular}{|l|c|}
\hline 1. Quality Level (QL) No. & 3 \\
\cline { 1 - 2 } 2. QL Determination No. & MSA-000074 \\
\hline 3. Engineering Job (EJ) No. & N/A \\
\hline 4. SSC ID & N/A $/ A$. \\
\hline 5. Building & N/A \\
\hline 6. Site Area & N/A \\
\hline
\end{tabular}

7. Introduction:

The Nuclear Data Management and Analysis System (NDMAS) manages irradiation experiment data collected under the Advanced Gas Reactor (AGR) Fuel Development and Qualification Program within the Advanced Reactor Technologies Technology Development Office. This technical evaluation describes the NDMAS database and reporting system that supports the AGR-5/6/7 irradiation experiment.

The AGR-5/6/7 irradiation experiment combines the fifth, sixth, and seventh planned irradiation campaigns of the United States Department of Energy AGR Fuel Development and Qualification Program. These combined irradiation tests will consist of fuel qualification tests (AGR-5/6) and a margin test (AGR-7) for the industrially produced uranium oxycarbide (UCO) tristructural isotropic (TRISO) coated particle fuel developed by the AGR Fuel Development and Qualification Program. The objective of the AGR-5/6/7 irradiation experiment is to establish the performance of UCO TRISO fuel fabricated using engineering-scale equipment in a production environment under and beyond normal operating conditions (PLN-5245, "AGR-5/6/7 Irradiation Experiment Test Plan").

In preparation for the AGR-5/6/7 experimental data, preliminary work has been done to ensure the data can be captured, processed, and delivered to the NDMAS web site as soon as the irradiation begins. Experimental data collected during AGR-5/6/7 (i.e., thermocouple temperature, gas flow rate, fission product release rate, gross gamma count, and Advanced Test Reactor [ATR] operational parameters) are captured automatically to the NDMAS database. Data derived from numerical simulation or other mathematical analyses (i.e., fast fluence, burnup, temperature, and fission product release-to-birth ratio) are captured to the database when provided by the researchers.

The NDMAS database is a relational database accessed via structured query language (SQL) and managed with Microsoft SQL Server. While select users can directly access the database, that is not the most convenient way to interact with the data. The NDMAS team constructs tables that combine related datasets, and delivers those data to researchers via graphs and spreadsheets on a Microsoft SharePoint-based website. The website pages will be used by members of the fuel irradiation team for monitoring irradiation conditions according to SPC-1749, "AGR-5/6/7 Irradiation Test Specification," by the physics modelers to access necessary model inputs, and by the nuclear engineering community to view and access data such as fuel temperatures, fission product release from capsules, and ATR operational parameters. This technical evaluation describes the AGR5/6/7 SharePoint website that represents the end state of the NDMAS data capture, processing and reporting system. The website contains tables of the measured and calculated data, graphs displaying the data, and links to source documents and references. As the NDMAS data collection and reporting system is in place before data are available for the relevant experiments, the data 
TEM-10300-1

$03 / 01 / 2012$

TECHNICAL EVALUATION

Page 3 of 20

Rev. 03

Title: $\quad$ NDMAS Database Reporting System for the AGR-5/6/7 Experiments

$\begin{array}{lllll}\text { TEV No.: } & 3236 & \text { Rev. No.: } 0 & \text { Project No.: 29412, } 23841 & \text { Date: 12/15/2017 }\end{array}$

processing currently points to data from previous experiments, to better illustrate the appearance of the final product.

8. If revision, please state the reason and list sections and/or pages being affected: Not a revision.

9. Conclusions/Recommendations:

N/A 
TEM-10300-1

$03 / 01 / 2012$

TECHNICAL EVALUATION

Page 4 of 20

Rev. 03

Title: $\quad$ NDMAS Database Reporting System for the AGR-5/6/7 Experiments

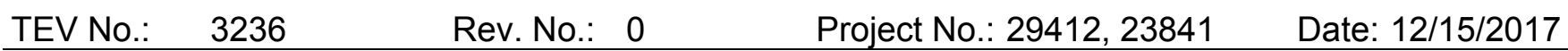

\section{CONTENTS}

PROJECT ROLES AND RESPONSIBILITIES 5

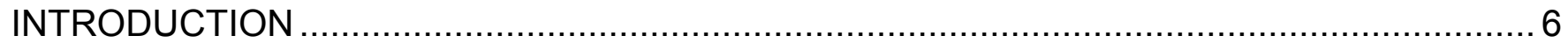

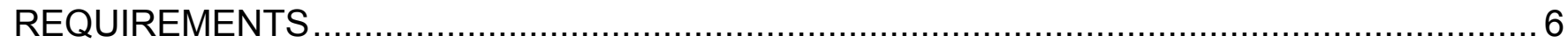

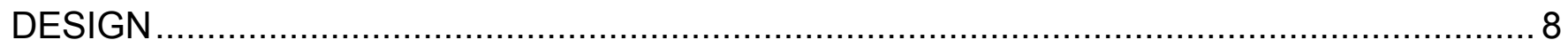

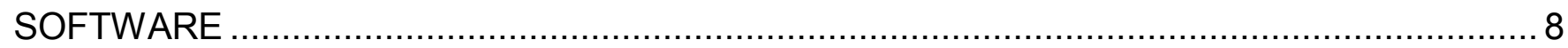

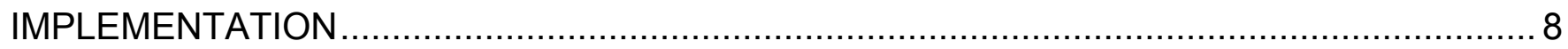

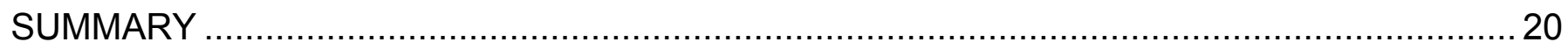

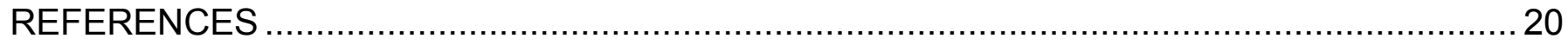


Rev. 03

Title: $\quad$ NDMAS Database Reporting System for the AGR-5/6/7 Experiments

TEV No.: $3236 \quad$ Rev. No.: 0

Project No.: 29412, 23841

Date: $12 / 15 / 2017$

\section{PROJECT ROLES AND RESPONSIBILITIES}

\begin{tabular}{|c|c|c|c|}
\hline Project Role & Name (Typed) & Organization & Pages covered (if applicable) \\
\hline Performer & Binh T Pham & $\mathrm{C} 220$ & \\
\hline Checker $^{a}$ & Mitchell A. Plummer & $\mathrm{C} 220$ & All \\
\hline Independent Reviewer ${ }^{b}$ & $\mathrm{~N} / \mathrm{A}$ & & \\
\hline CUI Reviewer ${ }^{c}$ & $\mathrm{~N} / \mathrm{A}$ & & \\
\hline Manager $^{d}$ & Nancy J. Lybeck & $\mathrm{C} 220$ & \\
\hline Requestor ${ }^{e}$ & Travis R. Mitchell & $\mathrm{C} 020$ & \\
\hline Nuclear Safety ${ }^{\mathrm{e}}$ & $\mathrm{N} / \mathrm{A}$ & & \\
\hline Document Owner & & $\mathrm{C} 620$ & \\
\hline Quality Engineer & Michelle T. Sharp & $\mathrm{H} 330$ & \\
\hline
\end{tabular}
a. Confirmation of completeness, mathematical accuracy, and correctness of data and appropriateness of assumptions.
b. Concurrence of method or approach. See definition, LWP-10106.
c. Concurrence with the document's markings in accordance with LWP-11202.
d. Concurrence of procedure compliance. Concurrence with method/approach and conclusion.
e. Concurrence with the document's assumptions and input information. See definition of Acceptance, LWP-10200.

NOTE: $\quad$ Delete or mark "N/A" for project roles not engaged. Include ALL personnel and their roles listed above in the eCR system. The list of the roles above is not all inclusive. If needed, the list can be extended or reduced. 
TEM-10300-1

$03 / 01 / 2012$

TECHNICAL EVALUATION

Page 6 of 20

Rev. 03

Title:

NDMAS Database Reporting System for the AGR-5/6/7 Experiments

TEV No.: 3236

Rev. No.: 0

Project No.: 29412, 23841

Date: $12 / 15 / 2017$

INTRODUCTION

The Nuclear Data Management and Analysis System (NDMAS) manages irradiation experiment data collected under the Advanced Gas Reactor (AGR) Fuel Development and Qualification Program within the Advanced Reactor Technologies Technology Development Office. This technical evaluation describes the NDMAS database and reporting system that supports the AGR-5/6/7 irradiation experiment.

The AGR-5/6/7 irradiation experiment combines the fifth, sixth, and seventh planned irradiation campaigns of the United States Department of Energy AGR Fuel Development and Qualification Program. These combined irradiation tests will consist of fuel qualification tests (AGR-5/6) and a margin test (AGR-7) for the industrially produced uranium oxycarbide (UCO) tristructural isotropic (TRISO) coated particle fuel developed by the AGR Fuel Development and Qualification Program. The objective of the AGR-5/6/7 irradiation experiment is to establish the performance of UCO TRISO fuel fabricated using engineering-scale equipment in a production environment under and beyond normal operating conditions (PLN-5245, “AGR-5/6/7 Irradiation Experiment Test Plan”).

In preparation for the AGR-5/6/7 experimental data, preliminary work has been done to ensure the data can be captured, processed, and delivered to the NDMAS web site as soon as the irradiation begins. Experimental data collected during AGR-5/6/7 (i.e., thermocouple temperature, gas flow rate, fission product release rate, gross gamma count, and Advanced Test Reactor [ATR] operational parameters) are captured automatically to the NDMAS database. Data derived from numerical simulation or other mathematical analyses (i.e., fast fluence, burnup, temperature, and fission product release-to-birth ratio) are captured to the database when provided by the researchers.

The NDMAS database is a relational database accessed via structured query language and managed with Microsoft SQL Server. While select users can directly access the database, that is not the most convenient way to interact with the data. The NDMAS team constructs tables that combine related datasets, and delivers those data to researchers via graphs and spreadsheets on a Microsoft SharePointbased website. The website pages will be used by members of the fuel irradiation team for monitoring irradiation conditions according to SPC-1749, "AGR-5/6/7 Irradiation Test Specification," by the physics modelers to access necessary model inputs, and by the nuclear engineering community to view and access data such as fuel temperatures, fission product release from capsules, and ATR operational parameters. This technical evaluation describes the AGR-5/6/7 SharePoint website that represents the end state of the NDMAS data capture, processing and reporting system. The website contains tables of the measured and calculated data, graphs displaying the data, and links to source documents and references. As the NDMAS data collection and reporting system is in place before data are available for the relevant experiments, the data processing currently points to data from previous experiments, to better illustrate the appearance of the final product.

\section{REQUIREMENTS}

Requirements for the AGR-5/6/7 Irradiation Monitoring website are as follows:

- $\quad$ The AGR-5/6/7 Irradiation Monitoring website will cover the combined fifth, sixth, and seventh experiments in a series. The website is located at https://htgr.inl.gov/htr/agrSite/agrIrrSite/AGR567IrrSite/SitePages/Home.aspx.

- $\quad$ The AGR-5/6/7 website will be designed to have the same look and feel as the websites built to cover irradiation data for the four already-completed experiments (AGR-1, AGR-2, and AGR-3/4).

- $\quad$ Access to the website will be controlled through the use of role-based security groups. Specifically, members of the SharePoint security groups, Team NGNP Customers US and Team 
Rev. 03

Title: $\quad$ NDMAS Database Reporting System for the AGR-5/6/7 Experiments

$\begin{array}{lllll}\text { TEV No.: } 3236 & \text { Rev. No.: } 0 & \text { Project No.: 29412, 23841 Date: 12/15/2017 }\end{array}$

NGNP Customers US Limited, will have read and download permissions to all website content. Members of the SharePoint security group, Team NGNP Developers, will have design and manage hierarchy permissions to the website.

- Web pages are generally organized by the irradiation and physics data streams according to PLN-5245, "AGR-5/6/7 Irradiation Experiment Test Plan." They include:

- $\quad$ Experimental data (updated daily during irradiation):

- $\quad$ ATR operating parameters: individual lobe power, neck shim position (in or out), outer shim control cylinder angular position, and regulatory rod position (inserted depth)

- $\quad$ Thermocouple temperatures

- $\quad$ Gas flow rates for neon and helium, total inlet flow, outlet flow, and leadout flow

- $\quad$ Pressure and moisture content for the sweep gas on the outlet side of the capsule

- $\quad$ Fission product release rate and release-to-birth ratio for 12 gaseous isotopes: $\mathrm{Kr}-85 \mathrm{~m}, \mathrm{Kr}-87, \mathrm{Kr}-88, \mathrm{Kr}-89, \mathrm{Kr}-90, \mathrm{Xe}-131 \mathrm{~m}, \mathrm{Xe}-133, \mathrm{Xe-135}, \mathrm{Xe-135m,} \mathrm{Xe-137,}$ $\mathrm{Xe}-138$, and $\mathrm{Xe}-139$

- $\quad$ Gross gamma counts

Calculated data (available after the end of each cycle):

- $\quad$ Fuel burnup

- $\quad$ Fast neutron fluence

- $\quad$ Fuel heat rate

- $\quad$ Fuel compact temperature and temperatures at thermocouple locations

- $\quad$ Each web page will provide relevant graphs and tables, as well as links to summary files in Microsoft Excel format, similar to those provided in web pages for the completed experiments (AGR-1, AGR-2, and AGR-3/4). In addition, there will be irradiation monitoring plots for the current cycle with higher resolution data, which can be used to identify any abnormal behavior indicating instrument failure or unexpected changes in capsule properties. These findings help manage capsule temperature to maintain fuel irradiation condition within its specification.

- Web page layout will include a standard footer across the bottom of the page and global navigation across the top of the page. The main page will include links to other pages displaying specific data streams in greater details.

- $\quad$ An introductory paragraph will be provided for each web page that describes the primary goals of the specific data stream, and the analyses and methods applied to data acquisition.

- Web pages will exclude disqualified data when their status is documented by an appropriate data qualification report. 
TEM-10300-1

$03 / 01 / 2012$

Rev. 03

Title: $\quad$ NDMAS Database Reporting System for the AGR-5/6/7 Experiments

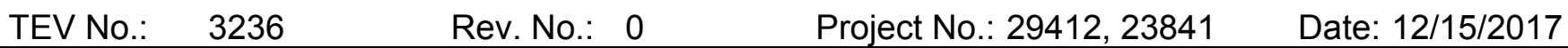

- $\quad$ A list of plans, reports, calculations, and data qualification reports relevant to the AGR-5/6/7 irradiation data will be provided on the website homepage. A link to the Electronic Document Management System will be provided if available, along with a non-record copy of the document uploaded to the SharePoint library when a Scientific and Technical Information Management System review has been performed on the document.

\section{DESIGN}

Key elements of the page design include:

- $\quad$ A wiki-style page that provides maximum flexibility in adding content to the page.

- $\quad$ A Site Pages library to store the wiki-style pages.

- A Site Assets library that holds pictures displayed on the web pages and Excel files that can be downloaded by users.

- $\quad$ A document library that holds documents associated with the program such as specification and plan documents and as-run analytical and data qualification reports. There are two content types for the library: 'document' and 'link to document.' They are organized by AGR experiment.

- $\quad$ SharePoint web parts that display views of libraries and lists.

- $\quad$ Inherited global and local navigation from the parent site.

- $\quad$ Page viewers will be used to display Hyper Text Markup Language (HTML) content stored on ndmasweb.inl.gov that was output from SAS, providing greater control of content and navigation within the results pages.

- $\quad$ A publishing system that makes web page revisions visible to customers only after they have been approved and republished.

\section{SOFTWARE}

Most of the software involved in developing contents of the web pages for the AGR-5/6/7 Irradiation Monitoring website is commercial off-the-shelf software. Codes used to extract data from the NDMAS vault, transform them into a format suitable for display and analysis, and store those data in a webaccessible location are managed under 562.41 "Software Management Plan and Life Cycle Documentation for Research and Development Activities."

Commercial, off-the-shelf software used to develop and display the web pages are:

- $\quad$ SAS Business Intelligence Platform, Version 9.4

- $\quad$ SharePoint Content Delivery Portal, Version 2013.

\section{IMPLEMENTATION}

The required security groups for prospective users of the AGR-5/6/7 Irradiation Monitoring website web pages, Team NGNP Customers US and Team NGNP Customers US Limited, already exist in SharePoint. New users may request an account through Idaho National Laboratory (INL's) Computer Account Information Management System by choosing the application NDMAS and submitting the "Request for Application Access," including an INL point of contact to confirm their need to access the data. NDMAS personnel will run new external users through INL's restricted party screening prior to granting access. Additionally, foreign nationals (whether INL employees or external customers) must have a security plan in place identifying their need to access NDMAS. 
TEM-10300-1

$03 / 01 / 2012$

TECHNICAL EVALUATION

Page 9 of 20

Rev. 03

Title: $\quad$ NDMAS Database Reporting System for the AGR-5/6/7 Experiments

TEV No.: $3236 \quad$ Rev. No.: $0 \quad$ Project No.: 29412, 23841

Date: $12 / 15 / 2017$

Web pages and the codes used to extract, transform, and load data that are displayed on the website are tracked in the Microsoft Team Foundation Server. Change requests are used to document requirements, testing, review, and approval for each code and each web page. Table 1 shows specific code used to extract, transform, and plot data that are displayed on the web pages; and web pages created within AGR-5/6/7 Irradiation Monitoring website. The Team Foundation Server numbers of associated change request are also included on the footnotes.

Table 1. Code and web pages for AGR-5/6/7 Irradiation Monitoring website.

\begin{tabular}{|c|c|c|}
\hline Code/Web Page & Purpose/Content & Update Frequency \\
\hline AGR_IRR_Data_Plot_V0_03.egp ${ }^{a}$ & $\begin{array}{l}\text { Extract irradiation data from the vault, } \\
\text { create ready-to-use SAS tables and store } \\
\text { them in the Fuel Mart. } \\
\text { Generate necessary plots and create html } \\
\text { pages for display on SharePoint pages. }\end{array}$ & Daily \\
\hline AGR_IRR_Data_Excel.egp ${ }^{a}$ & $\begin{array}{l}\text { Output data to Excel files used for } \\
\text { download from the web pages. }\end{array}$ & Daily \\
\hline Fuel Irradiation ${ }^{\mathrm{b}}$ (Figure 1) & $\begin{array}{l}\text { Add overview and documents of AGR-5/6/7 } \\
\text { experiment to the Fuel Irradiation } \\
\text { homepage. }\end{array}$ & As needed \\
\hline $\begin{array}{l}\text { AGR-5/6/7 Irradiation }{ }^{\mathrm{b}} \text { (Figure } 2 \\
\text { through Figure } 5 \text { ) }\end{array}$ & $\begin{array}{l}\text { Display main content of irradiation } \\
\text { measurements and calculated data used for } \\
\text { monitoring of capsule experimental } \\
\text { condition. } \\
\text { Provide data links for download. } \\
\text { Provide links to the other four web pages, } \\
\text { Thermocouple (TC) Data, Gas Flow Rates, } \\
\text { Fission Product Data, and Physics Data. } \\
\text { Provide space for announcing events of } \\
\text { interest that occurred during irradiation, } \\
\text { which can be added or removed by the fuel } \\
\text { irradiation team members using Newsfeed } \\
\text { on SharePoint. }\end{array}$ & $\begin{array}{l}\text { Daily and upon } \\
\text { request }\end{array}$ \\
\hline $\begin{array}{l}\text { Thermocouple (TC) Data } \\
\text { (Figure 6) }\end{array}$ & $\begin{array}{l}\text { Display temperature data and status of } \\
54 \text { TCs in AGR-5/6/7 capsules }\end{array}$ & $\begin{array}{l}\text { At the end of each } \\
\text { cycle }\end{array}$ \\
\hline Gas Flow Rates ${ }^{\mathrm{b}}$ (Figure 7) & $\begin{array}{l}\text { Display download link and summary plots } \\
\text { for gas flow rates in five capsules. }\end{array}$ & $\begin{array}{l}\text { At the end of each } \\
\text { cycle }\end{array}$ \\
\hline Fission Product Data ${ }^{b}$ (Figure 8) & $\begin{array}{l}\text { Display download link and summary plots } \\
\text { for fission product release rate and } \\
\text { release-to-birth ratio in five capsules. }\end{array}$ & $\begin{array}{l}\text { At the end of each } \\
\text { cycle }\end{array}$ \\
\hline Physics Data ${ }^{b}$ (Figure 9) & $\begin{array}{l}\text { Display the results of depletion and thermal } \\
\text { analyses for fuel compacts (the end of } \\
\text { irradiation data will be added when the } \\
\text { irradiation is completed). }\end{array}$ & With new data \\
\hline
\end{tabular}


TEM-10300-1

$03 / 01 / 2012$

TECHNICAL EVALUATION

Page 10 of 20

Rev. 03

Title: $\quad$ NDMAS Database Reporting System for the AGR-5/6/7 Experiments

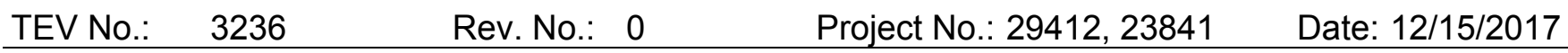

a Codes used for processing AGR-5/6/7 data are the same as codes for AGR-1, AGR-2, and AGR-3/4, which are located in the Folder IlisasappINDMAS_CodelNDMAS_2.0\AGR_VA. These codes will be modified to accommodate the increased number of TCs in the AGR-5/6/7 capsules. Documentation of the most recent code testing is in TFS CR \#2918 for AGR_IRR_Data_Plot_V0_03.egp code and CR \#2866 for

AGR_IRR_Data_Excel.egp code.

b Web pages in the AGR-5/6/7 Irradiation Monitoring website are tracked by TFS CR \#2916.

A screen shot of the homepage for the Fuel Irradiation website is provided in Figure 1. A short description and two currently available documents for the AGR-5/6/7 experiment were added to the Fuel Irradiation homepage. Screen shots provided in Figure 2 through Figure 9 highlight important contents of web pages within the AGR-5/6/7 Irradiation Monitoring website. Since the AGR-5/6/7 irradiation has not yet started, plots in all web pages are based on similar data for the completed AGR irradiations (either AGR-1 or AGR-3/4) for illustration purposes.

As irradiation progresses and additional data are captured automatically to the NDMAS database, relevant plots and data tables displayed in the AGR-5/6/7 web pages will update on a regular basis as required by the AGR irradiation management team. AGR-5/6/7 Irradiation Monitoring website is designed to assist experimental monitoring according to the test plan to maintain irradiation conditions within the fuel irradiation specification. For fuel temperature control, TC performance is closely monitored (primarily for control TCs) for drift failures so that the control TC set point for the gas mix system can be adjusted as necessary to compensate for TC drift.

In addition, data are provided to internal and external researchers for analysis by the download links on the web pages. For completed cycles, daily averages are available for downloads in Excel files stored in the Site Assets library. For the current cycle, higher resolution data are provided using SAS stored processes that download the most current data. Different formats and organization of data can be made available upon request. 
TEM-10300-1

$03 / 01 / 2012$

TECHNICAL EVALUATION

Page 11 of 20

Rev. 03

Title: $\quad$ NDMAS Database Reporting System for the AGR-5/6/7 Experiments

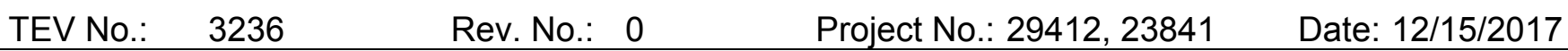

NDMAS
Fuel Fabrication
AGR-1 Irradiation
AGR-2 Irradiatiation
AGR-3/4 Irradiation
AGR-2 Irradiation (FR)
AGR-2 Irradiation (S.A.)
AGR-2 Irradiation (U.S.)
AGR-5/6/7 Irradiation
Fuel Post-Irradiation
Examination
Fuel Compact Data
Technical Coordination
Team
AGR Data Qualification
Status

ATR OPS HPRR VHTR - Methods NDMAS Team T-MIST, EDIT LINKS

Search this site $\quad 0$

Nuclear Data Management and Analysis System > High Temperature Reactor > Fuel Deveiopment and Qualification > Fuel Irradiation

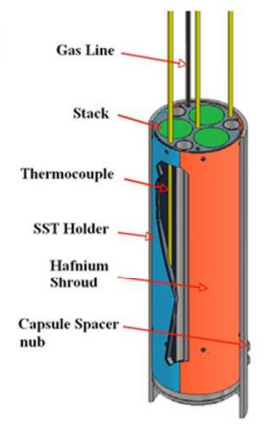

Advanced Gas Reactor Fuel Irradiation Experiments

The objective of the Advanced Gas Reactor (AGR) Fuel Irradiation Campaign is to qualify the low-enriched tri-structural isotropic (TRISO) coated particle fuel for use in high-temperature gascooled reactors. Fuel Irradiation activities provide data on fuel performance during irradiation to support fuel process development, qualify a fuel design and fabrication process for normal operating conditions, and support development and validation of fuel performance and fission product transport models and codes. The irradiated fuel and materials are also used for Post Irradiation Examination (PIE) and safety testing (PLN-3636). The fuel irradiation campaign consists of seven irradiation tests, designated as AGR-1 through AGR-7. All experimental data from the AGR experiments are captured and processed by the Nuclear Data Management and Analysis System (NDMAS). NDMAS processes AGR data into a secure Structured Query Language Server database, performs testing on and analysis of the data for anomaly identification, presents the data via an access-controlled web portal, and documents the qualification status of the data. The AGR data streams included in these web pages include both irradiation monitoring data and calculated data for each capsule in the AGR experiments. The monitoring data include thermocouple (TC) temperatures, sweep gas flow rates, and fission product monitoring system data (release rates, release-rate-to-birth-rate ratios [R/BS], and gross gamma counts). The calculated data include results from neutronic analysis (heat rate, fast neutron fluence, burnup, and fission product inventory) and thermal analysis ( $T \mathrm{C}$ and fuel compact temperatures). Details regarding the qualification status of irradiation monitoring data and physics data can be found in the documents listed below. Gross gamma data are not evaluated for qualification purposes. Four experiments, AGR-1, AGR-2 and AGR-3/4, have been completed and the combined AGR-5/6/7 experiment is ongoing:

AGR-1: The AGR-1 test train was comprised of six capsules (see figure) containing laboratory-scale produced uranium oxycarbide (UCO) fuel. The instrumented test train was irradiated in the arge B-10 position in Advanced Test Reactor (ATR) at INL from December 2006 through November 2009, resulting in 620.2 effective full power days (EFPDs) and spanning thirteen ATR cycles, $138 \mathrm{~B}$ through $145 \mathrm{~A}$.

AGR-2: The AGR-2 test train was comprised of six capsules containing large-scale coater produced uranium carbide/oxide (UCO) and uranium dioxide (UO2) fuel from the United States (U.S) and UO2 fuel provided from France and South Africa. The instrumented test train was irradiated in the large B-12 position in ATR from June 2010 through mid-October 2013, resulting in 559.2 EFPDs and spanning twelve regular ATR cycles, $147 \mathrm{~A}$ through $154 \mathrm{~B}$. The test train was stored in the water canal during the Powered Axial Locator Mechanisms (PALM) cycle150A. The test train remained in the reactor during low power cycle 152A, when ATR core was raised to low power for a few hours. The test train was temporarily relocated to the I-24 location during the second PALM Cycle, 153B.

AGR-3/4: The AGR-3/4 test train was comprised of twelve capsules containing designed-to-fail fuel particles to provide data on fission product diffusivities in fuel kernels and sorptivities and diffusivities in compact matrix and graphite materials. These combined experiments were irradiated in the northeast flux trap position in ATR from December 2011 through mid-April 2014, resulting in 369.1 EFPDs and spanning seven regular ATR cycles, 151 A through 155B. The test train remained in the reactor during low power cycle 152A. The test train was stored in the water canal during outage cycle 153A and PALM cycle 153B.

AGR-5/6/7: The AGR-5/6/7 test train was comprised of five capsules containing 194 UCO fuel compacts fabricated by a United States-based commercial vendor using production-scale equipment. These combined experiments are also irradiated in the northeast flux trap position in ATR from March 2018 and expected to irradiatiate for 500 EFPDs. The irradiation campaign will test fuel beyond its operating temperature envelope so that some measurable level of fuel failure is expected to occur.

Data Qualification and Analysis Documents

The reports listed below are not record copies, and may not represent the most recent version. The INL Electronic Document Management System (EDMS) should be used to provide the record copy of the document. The ECARs listed below have a direct link to EDMS. Unfortunately, these links will not work for users outside the INL firewall. External users who wish to obtain a copy of a document stored in EDMS should contact Mitch Plummer, 208-526-2785.

Name Documentio

Experiment : AGR-1 (9)

Experiment : AGR-2 (8)

Experiment : AGR-3/4 (9)

$\triangle$ Experiment : AGR-5/6/7 (2)

AGR-567 Irradiation Test Specification SPC-1749

AGR-567 Irradiation Test Plan

Point-of-contacts:

Fuel irradiation: Michael Davenport 208.526.6214

Fission product release and gross gamma: Dawn Scates, 208.526 .5503

Neutronic analysis: Jim Sterbentz, 208.526.9810

Thermal analysis: Grant Hawkes, 208.526.8767

Web page and data download: Binh Pham, 208.526.8078

Security/Privacy
NQA-1 Compliance
ART
DOE Idaho
Contact Us

Copyright $\odot 2014$ Idaho National Laboratory

Figure 1. Fuel Irradiation website homepage showing the overview and documents of the AGR-5/6/7 experiment. 
TEM-10300-1

$03 / 01 / 2012$

TECHNICAL EVALUATION

Page 12 of 20

Rev. 03

Title: $\quad$ NDMAS Database Reporting System for the AGR-5/6/7 Experiments

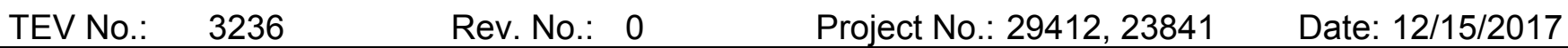

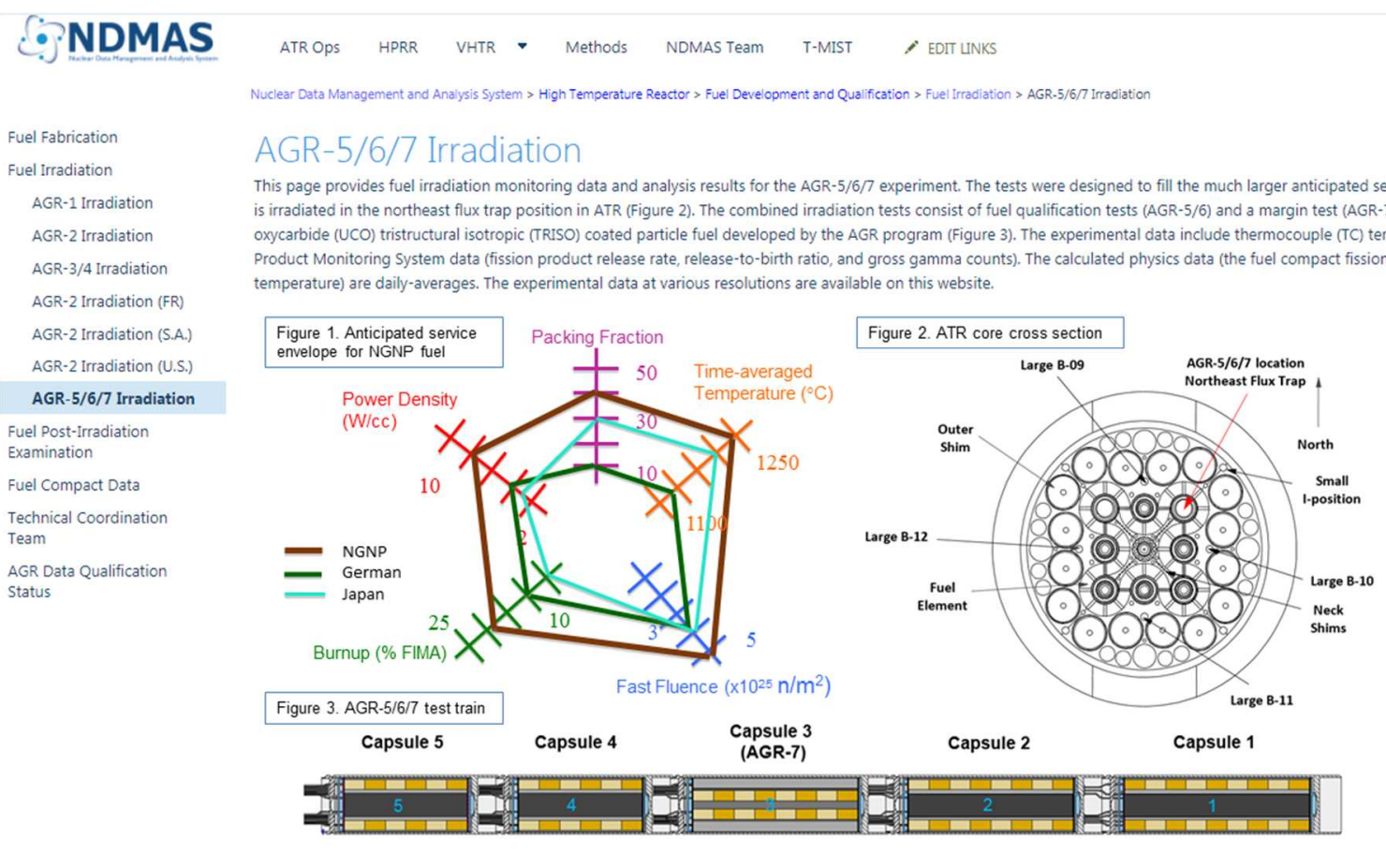

AGR-5/6/7 Irradiation Monitoring

Plots are based on hourly averages for current cycle and on daily-averages for all cycles.

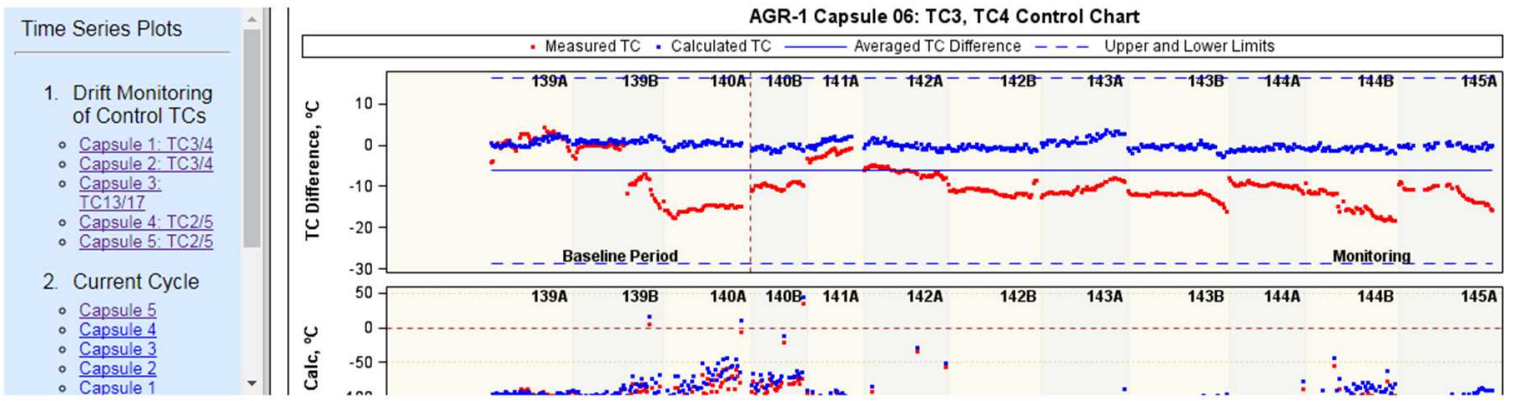

Data Downloads Webpages for Completed Cycles

5-minute TC temperature, neon fraction, gas flow, and gross gamma count for the current cycle.

Daily average TC temperature, neon fraction, gas flow, fission product release and $\mathrm{R} / \mathrm{B}$ of $\mathrm{Kr}-85 \mathrm{~m}, \mathrm{Kr}$ 88 , and $\mathrm{Xe}-138$, and gross gamma count for each capsule in separate spreadsheet.

Daily ATR operating parameters including lobe powers, outer shim control cylinder and neck shim positions, which are inputs to the JMOCUP depletion analysis. This file also contains daily neon fraction data for each capsule, which are inputs to the ABAQUS thermal analysis.

\begin{abstract}
TC Temperature Display TC status, summary plot, and control charts for TC drit monitoring

Gas Flow Rate Display the download links and summary plots for neon inlet

Fission Product Release Display the download links for isotope release rate and release-to-birth ratio and summary plots for releases and gross gamma count dat

Physics Data Display the depletion and thermal analyses data
\end{abstract}

Experimental Event Announcements

Figure 2. Completed AGR-5/6/7 Irradiation web page (the Irradiation Monitoring window is intentionally squeezed to provide a better overview of the website content and AGR-1 data was used as an example). 
TEM-10300-1

$03 / 01 / 2012$

TECHNICAL EVALUATION

Page 13 of 20

Rev. 03

Title: $\quad$ NDMAS Database Reporting System for the AGR-5/6/7 Experiments

TEV No.: 3236

Rev. No.: 0

Project No.: 29412, 23841

Date: $12 / 15 / 2017$

AGR-5/6/7 Irradiation Monitoring

Plots are based on hourly averages for current cycle and on daily-averages for all cycles.



Figure 3. AGR-5/6/7 Irradiation Monitoring window showing example of drift monitoring for a pair of TCs, which will be applied to the primary and secondary control TCs (plots shown are for one TC pair in AGR-1, Capsule 6). 
Rev. 03

Title: $\quad$ NDMAS Database Reporting System for the AGR-5/6/7 Experiments

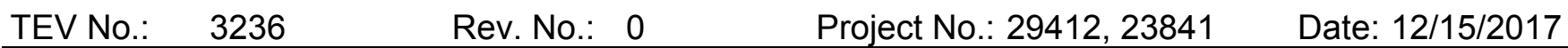

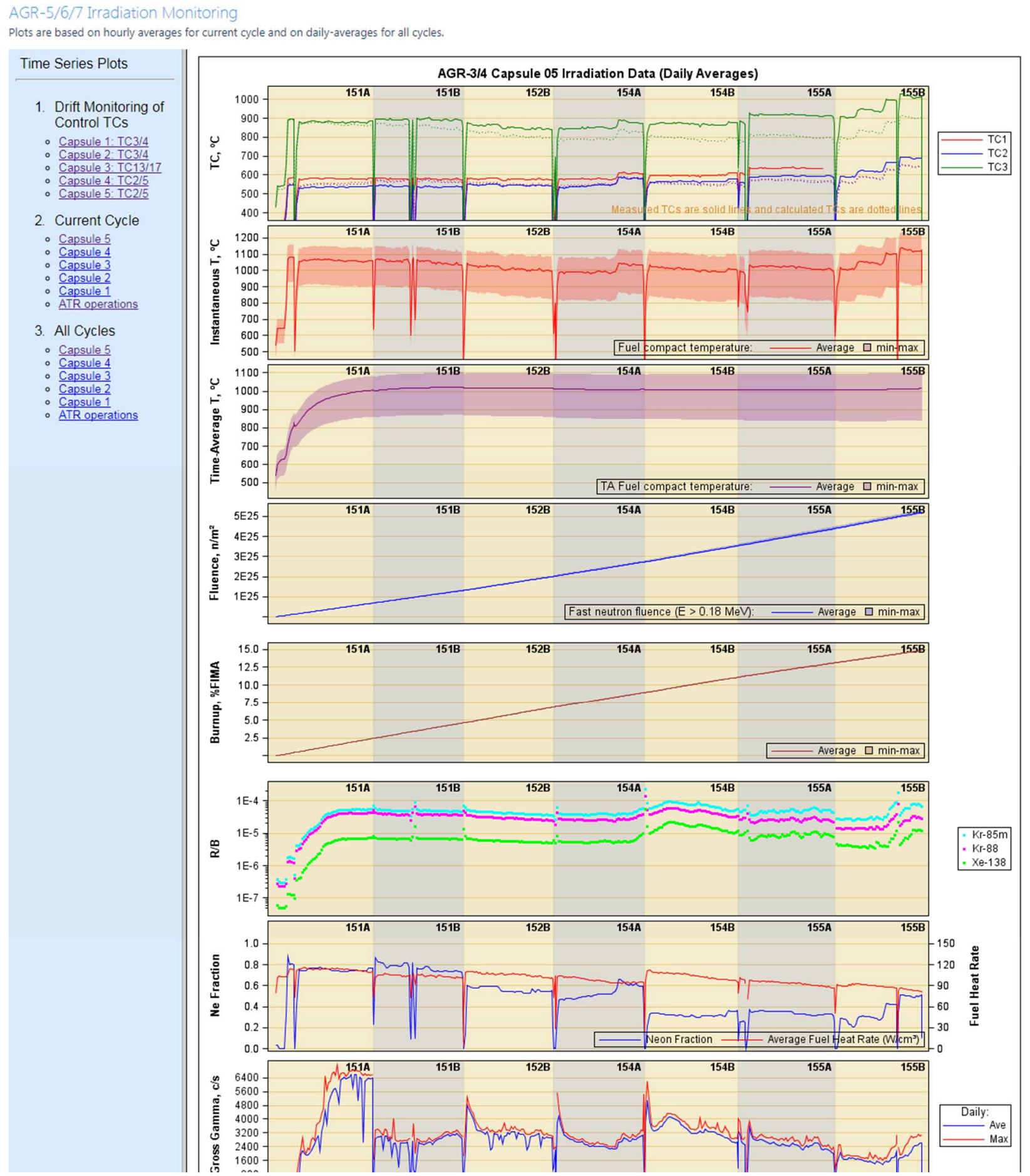

Figure 4. AGR-5/6/7 Irradiation Monitoring window showing graphical summary plots for all cycles used to monitor experimental irradiation conditions (similar plots for the current cycle based on higher resolution data can be used to capture detailed data trends for better understanding of the test conditions and AGR$3 / 4$ data was used as an example). 
Rev. 03

Title: $\quad$ NDMAS Database Reporting System for the AGR-5/6/7 Experiments

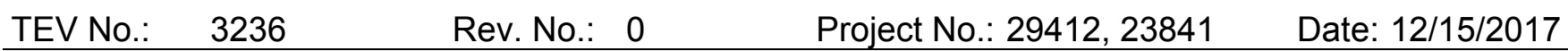

\section{AGR-5/6/7 Irradiation Monitoring}

Plots are based on hourly averages for current cycle and on daily-averages for all cycles.



Figure 5. AGR-5/6/7 Irradiation Monitoring window showing an example of graphical summary plots for ATR operational parameters for Cycle 161A. This plot helps interpret the AGR-5/6/7 experimental conditions. 
Rev. 03

Title: $\quad$ NDMAS Database Reporting System for the AGR-5/6/7 Experiments

TEV No.: $\quad 3236$

Rev. No.: 0

Project No.: 29412, 23841

Date: $12 / 15 / 2017$

\section{NDMAS}

ATROPS HPRR VHTR Methods NDMASTeam T-MIST EDIT LINKS

Fuel Fabrication

Fuel Irradiation

AGR-1 Irradiation

AGR-2 Irradiation

AGR-3/4 Irradiation

AGR-2 Irradiation (FR)

AGR-2 Irradiation (S.A.)

AGR-2 Irradiation (U.S.)

AGR-5/6/7 Irradiation

Fuel Post-Irradiation

Examination

Fuel Compact Data

Technical Coordination

Team

AGR Data Qualification

Status

\section{Thermocouple (TC) Data}

AGR-5/6/7 capsules were equipped with a larger number of TCs to provide backup for the maximum extent of irradiation in case of failure of the control TC. The image on the left shows TC positions in Capsules 1 and 3 with the red circles indicating location of the primary control TCS. The table on the right shows the number of TCS with the primary and secondary control TC in parentheses and list of failed TCS during irradiation for the 5 AGR-5/6/7 capsules, which will be timely updated.
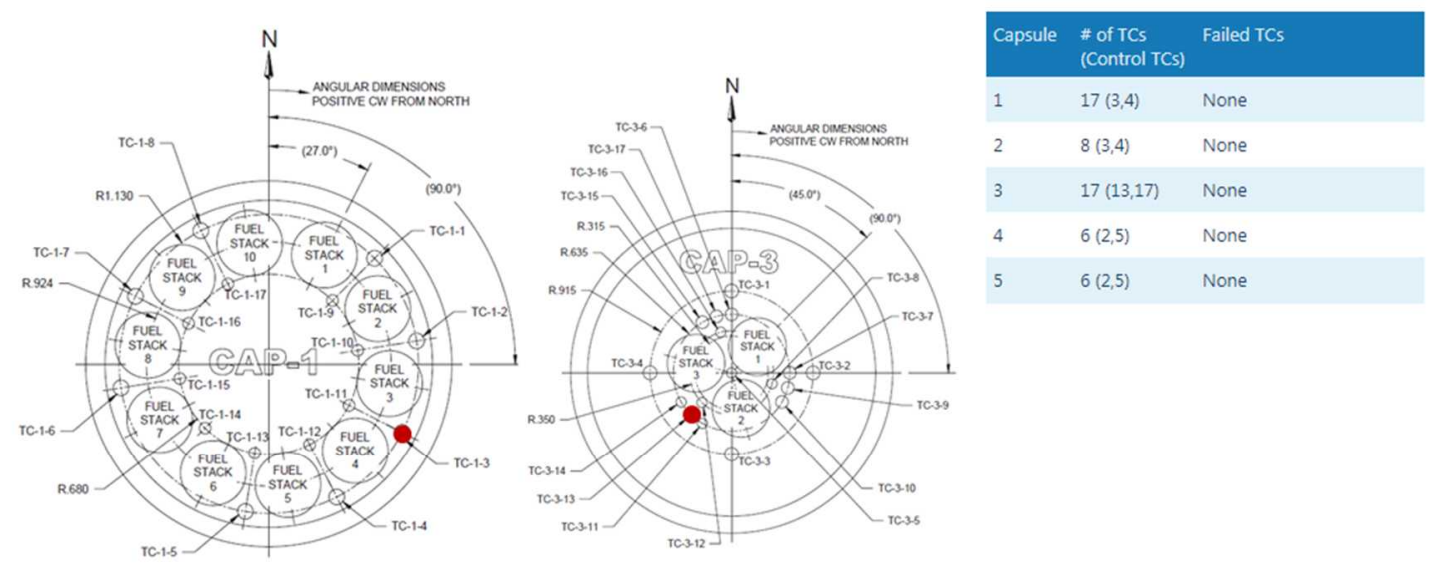

Graphical Summary Plots

Data are daily averages taken from TCS before their failure date, as determined in the irradiation data qualification process.

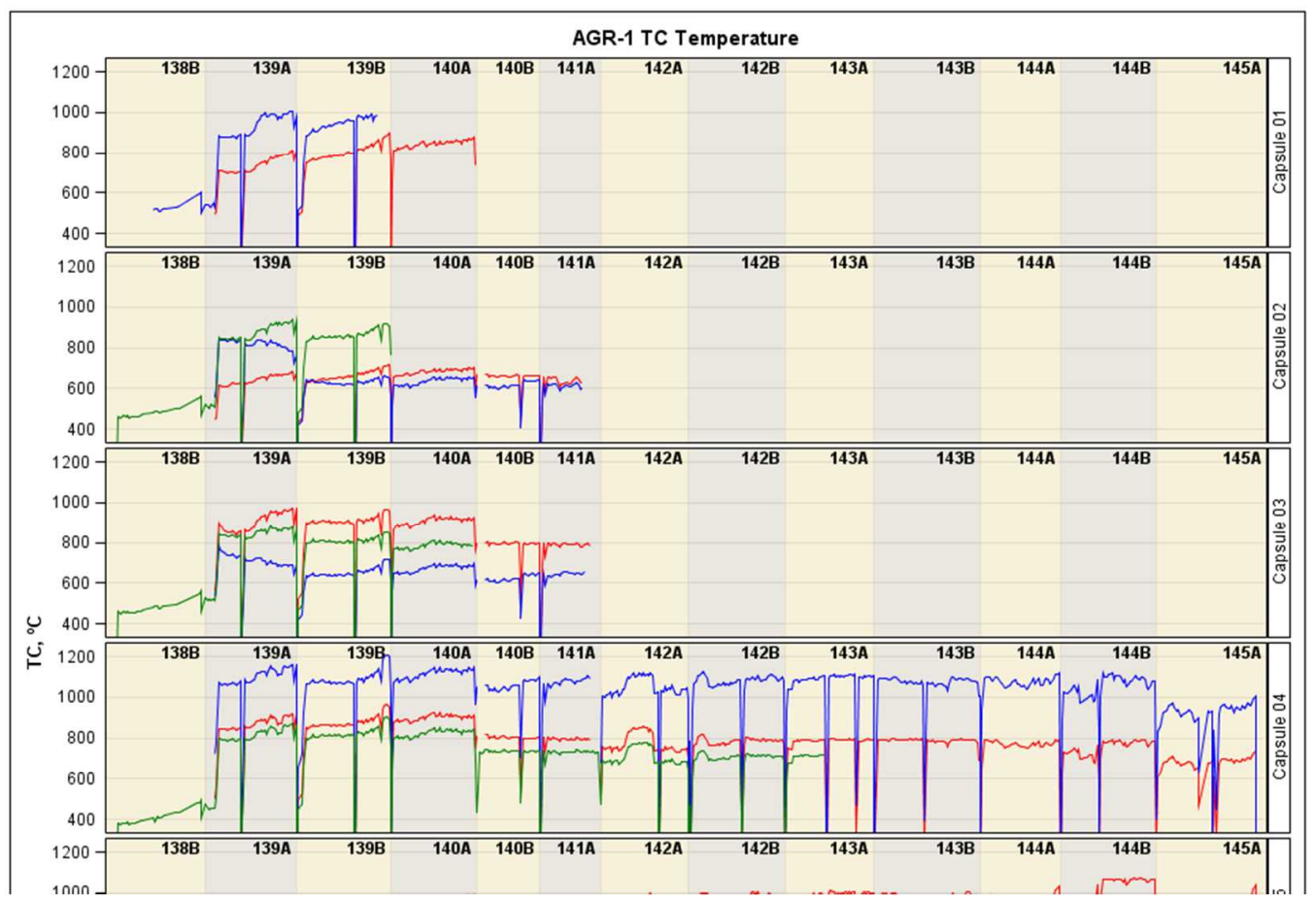

Figure 6. Thermocouple (TC) Data web page, accessed on the AGR-5/6/7 Irradiation Monitoring website, showing TC status and summary plot for all AGR-5/6/7 TCs (summary plot is based on AGR-1 TCs). This web page can be used to monitor TC performance and capture TC failures. 
Rev. 03

Title: $\quad$ NDMAS Database Reporting System for the AGR-5/6/7 Experiments

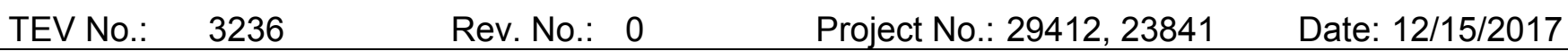
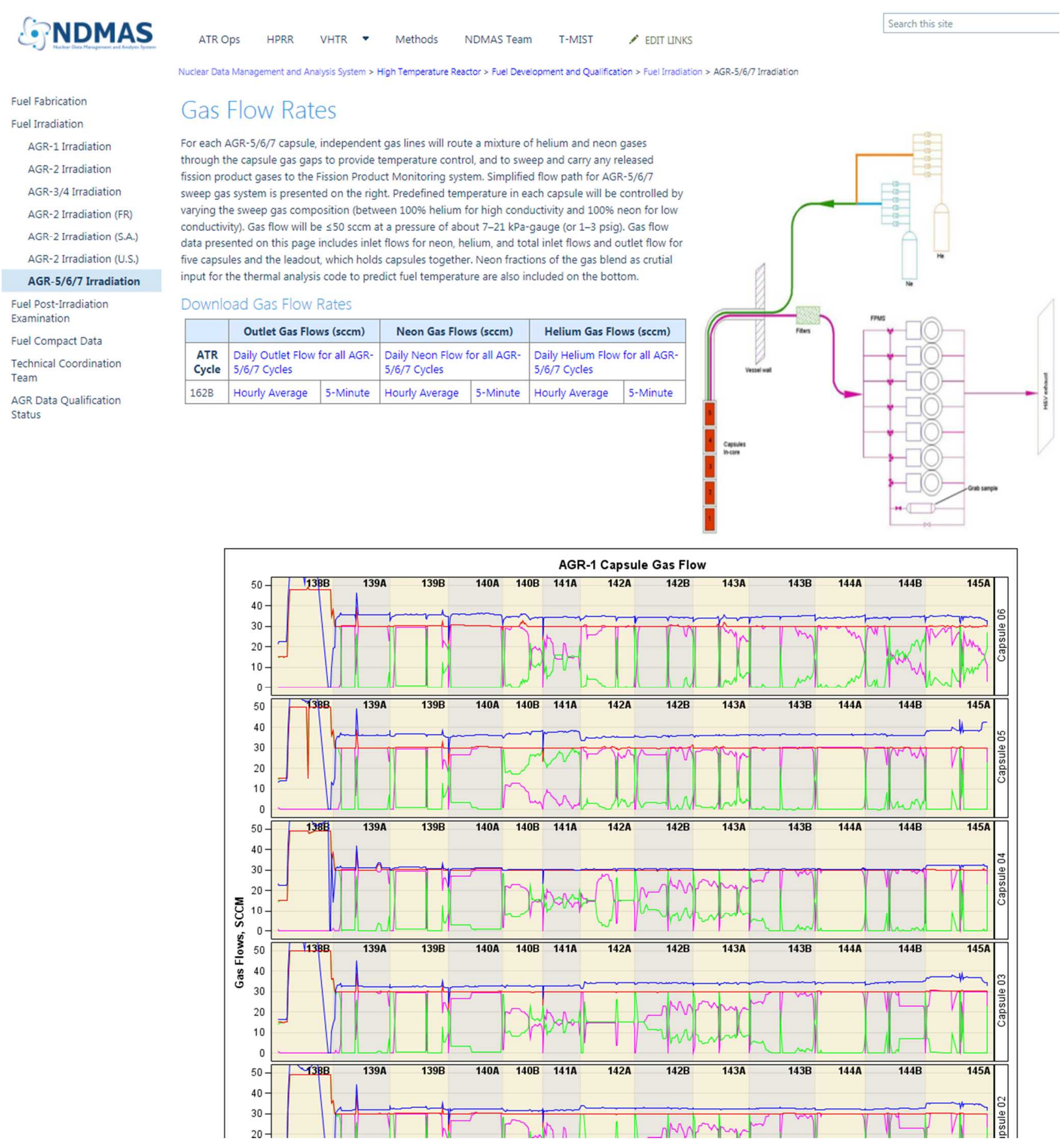

Figure 7. Gas Flow Rates web page, accessed on the AGR-5/6/7 Irradiation Monitoring website, showing data download links and graphical summary plots for neon, helium, and outlet flows, which can be used for the Fission Product Monitoring System team to access flow rate data and for monitoring the gas flow system and AGR-1 data was used as an example 
TEM-10300-1

$03 / 01 / 2012$

TECHNICAL EVALUATION

Page 18 of 20

Rev. 03

Title: $\quad$ NDMAS Database Reporting System for the AGR-5/6/7 Experiments

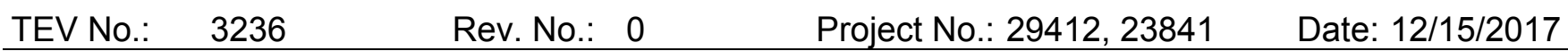

$\because$ NDMAS ATR Ops hPRR VHTR Methods NDMASTeam T-MIST , EDT LinkS
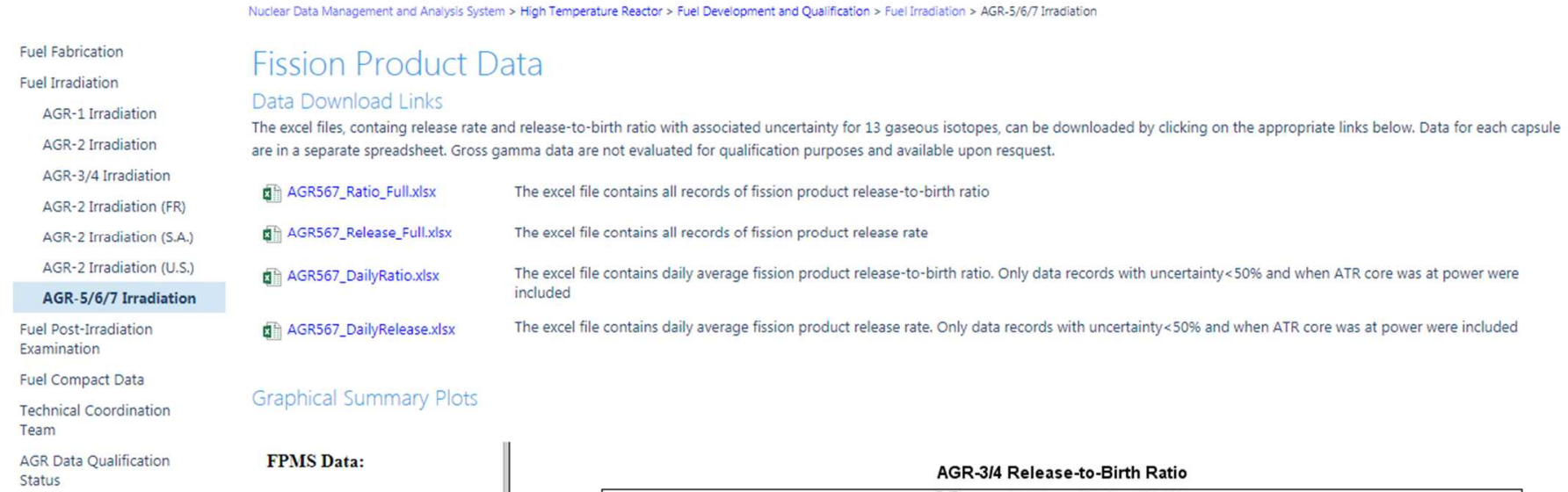

Graphical Summary Plots

FPMS Data:
Release-to-Birth Ratio
Release Rate
Gross Gamma Count

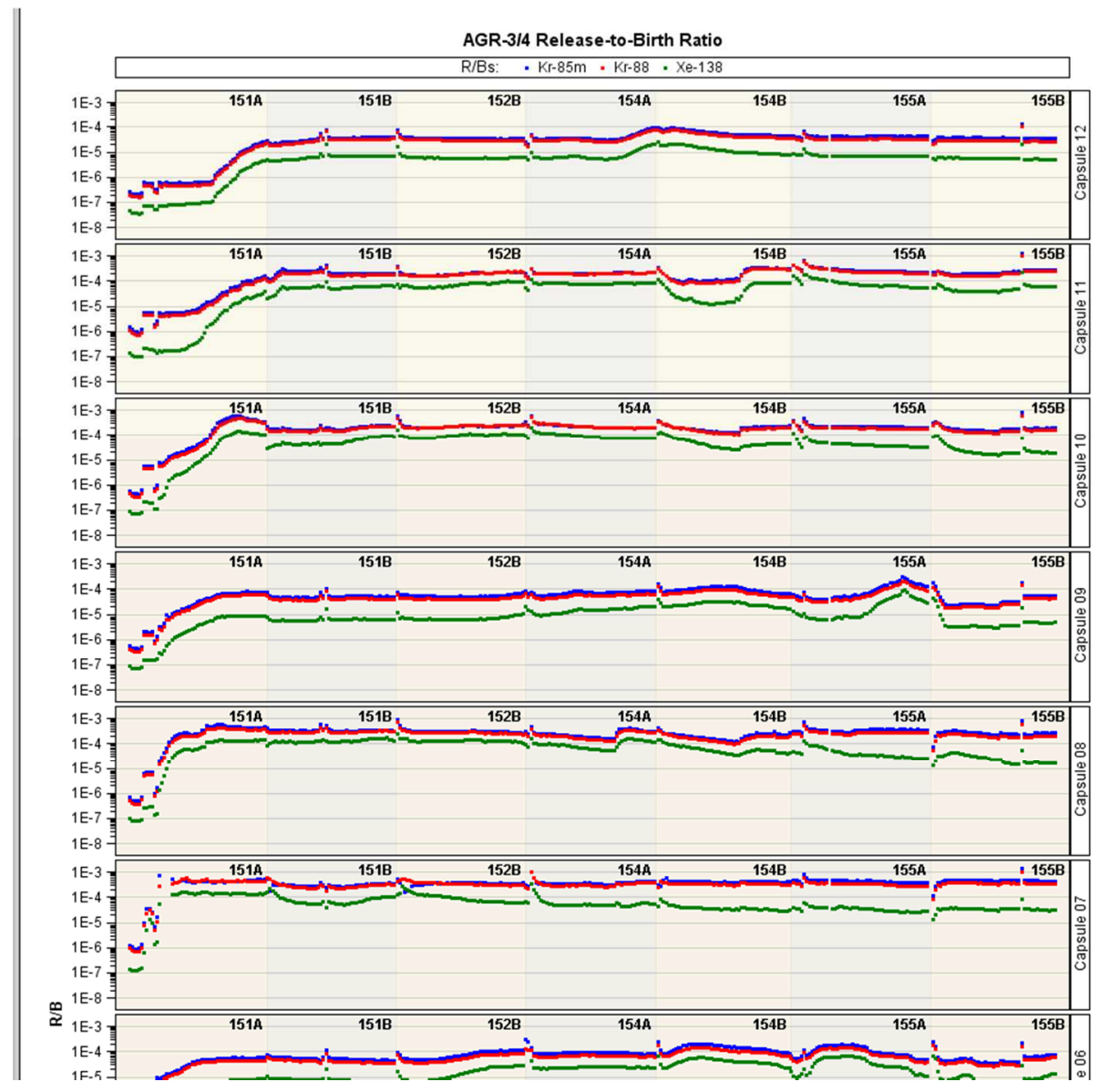

Figure 8. Fission Product Data web page, accessed on the AGR-5/6/7 Irradiation Monitoring website, showing the download links for isotope release rate and release-to-birth ratio and summary plots for releases and gross gamma count data, which can be used to access data and for monitoring the gross gamma counts and AGR-3/4 data was used as an example. 
TEM-10300-1

$03 / 01 / 2012$

TECHNICAL EVALUATION

Page 19 of 20

Rev. 03

Title: $\quad$ NDMAS Database Reporting System for the AGR-5/6/7 Experiments

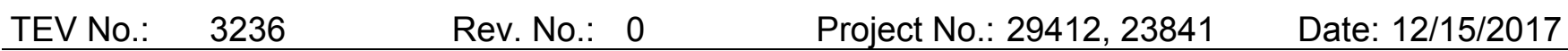

NDMAS atrops hPRR VhTR - Methods nDMAS Team T-Mist ; EDIt Links

Fuel Fabrication
Fuel Irradiation
AGR-1 Irradiation
AGR-2 Irradiation
AGR-3/4 Irradiation
AGR-2 Irradiation (FR)
AGR-2 Irradiation (S.A.)
AGR-2 Irradiation (U.S.)
AGR-5/6/7 Irradiation
Fuel Post-Irradiation
Examination
Fuel Compact Data
Technical Coordination
Team
AGR Data Qualification
Status

Nuclear Data Management and Analysis System > High Temperature Reactor > Fuel Development and Qualification > Fuel Irradiation > AGR-5/6/7 Irradiation

\begin{abstract}
Physics Data
The physics data are calculated results from depletion and thermal analyses. The neutronics data were reported in ECAR-xxxx, which include daily fuel fission power (MW per half of compact), fast neutron fluence $\left(\mathrm{n} / \mathrm{cm}^{2}\right)$, burnup (\%FIMA), and end-of-irradiation nuclide inventory (moles) for 194 fuel compacts placed in five capsules; and heat rate $\mathrm{W} / \mathrm{cm}^{3}$ ) for capsule components. The fuel compact heat rate in $\mathrm{W} / \mathrm{cm}^{3}$ included in the below summary plots were converted from fuel fission power stored in NDMAS database as Heat Rate=Fission power $1,323,438$. The thermal data were reported in ECAR-xxxx, which include daily temperature $\left({ }^{\circ} \mathrm{C}\right)$ of 194 fuel compacts and 54 TC locations. Projecttions of fuel burnup and fast neutron fluence are presented on the plots and estimations of temperature distribution of fuel compacts and graphite holders for one time step during irrdaiation are presented on the image below for each of five capsules (PLN-5245). The as-run physics data will be added as they become available.
\end{abstract}
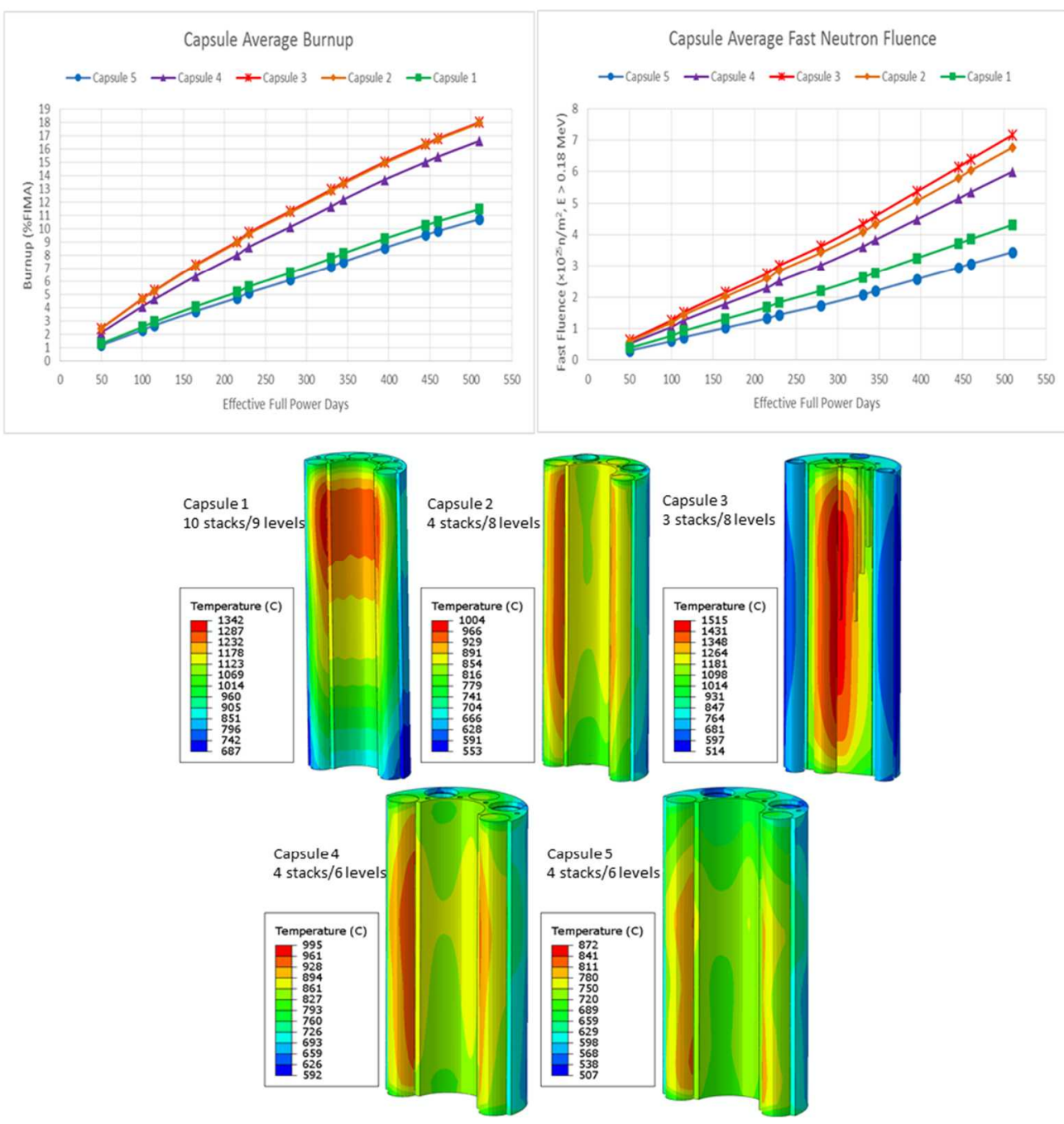

Figure 9. Physics Data web page, accessed on the AGR-5/6/7 Irradiation Monitoring website, displays fuel depletion analysis and thermal analysis data, which can provide calculated physics and thermal parameters of irradiated fuel. These data are expected after the end of each cycle. 
TEM-10300-1

$03 / 01 / 2012$

TECHNICAL EVALUATION

Page 20 of 20

Rev. 03

Title: $\quad$ NDMAS Database Reporting System for the AGR-5/6/7 Experiments

$\begin{array}{lllll}\text { TEV No.: } 3236 & \text { Rev. No.: } 0 & \text { Project No.: } 29412,23841 & \text { Date: } 12 / 15 / 2017\end{array}$

\section{SUMMARY}

In preparation for the start of AGR-5/6/7, new metadata entries have been made in the database to facilitate capturing the associated measurement parameters. The script used to automatically capture the experimental data collected is ready to process experimental data once the experiment has been installed in the reactor. Codes have been created to stage data for delivery and generate plots needed to support the experimental monitoring and as-run simulations.

The web pages for the AGR-5/6/7 Irradiation Monitoring website have been developed in SharePoint 2013 using a design similar to that of previous AGR irradiation web pages on the NDMAS website. These pages represent an end-state of the NDMAS data collection, processing and reporting system. As irradiation progresses, additional data are captured automatically to the NDMAS database, and relevant plots and data tables displayed in AGR-5/6/7 web pages will be updated on a regular basis as required by the AGR irradiation management team. This website was developed to assist experimental monitoring according to the test plan to maintain irradiation conditions within the fuel irradiation specification. In addition, up-to-date data are provided to internal and external researchers for analysis by the download links on the web pages.

\section{REFERENCES}

562.41, "Software Management Plan and Life Cycle Documentation for Research and Development Activities."

PLN-5245, "AGR-5/6/7 Irradiation Experiment Test Plan”

SPC-1749, “AGR-5/6/7 Irradiation Test Specification” 